\title{
Influence of hyperbaric oxygen therapy on bone metabolism in patients with neoplasm
}

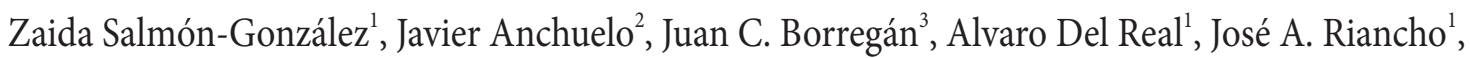 \\ Carmen Valero ${ }^{1}$ \\ ${ }^{1}$ Department of Internal Medicine, Hospital Marqués de Valdecilla-IDIVAL, University of Cantabria, Santander, Spain \\ ${ }^{2}$ Service of Radiation Oncology, Hospital Marqués de Valdecilla, Santander, Spain \\ ${ }^{3}$ Service of Intensive Care, Hospital Marqués de Valdecilla Santander, Spain
}

\section{ABSTRACT}

Background: Hyperbaric oxygen therapy (HBOT) is useful in the treatment of complications due to radiotherapy in patients with neoplasm. Its effects on bone metabolism are unclear. In our study, we analyzed the effects of HBOT on bone remodeling in oncological patients with radiotherapy.

Materials and methods: Prospective clinical study in 23 patients with neoplasms undergoing treatment with HBOT due to complications of radiotherapy (hemorrhagic cystitis, proctitis or radionecrosis) and 25 patients with chronic anal fissure. The average number of HBOT sessions was $20 \pm 5$ (100\% oxygen, 2.3 atmospheres and 90 min per day). Serum levels of aminoterminal propeptide of type I collagen (P1NP), C terminal telopeptide of type I collagen (CTX), alkaline phosphatase (AP), 25hydroxyvitamin D (25-OHD), parathyroid hormone (PTH), were measured at 3 time points: T0 (before beginning HBOT), T1 (at the end of HBOT) and T2 (6 months after HBOT).

Results: At baseline, the patients with neoplasm have higher bone turnover than those with anal fissure. These differences were $41 \%$ in CTX $(0.238 \pm 0.202 \mathrm{ng} / \mathrm{mL}$ in neoplasm and $0.141 \pm 0.116 \mathrm{ng} / \mathrm{mL}$ in fissure; $p=0.04), 30 \%$ for PTH $(46 \pm 36 \mathrm{pg} / \mathrm{mL}$ in neoplasm and $32 \pm 17 \mathrm{pg} / \mathrm{mL}$ in fissure; $\mathrm{p}=0.04$ ) and $15 \%$ for alkaline phosphatase ( $80 \pm 24 \mathrm{U} / \mathrm{L}$ in neoplasm and $68 \pm 16$ $\mathrm{U} / \mathrm{L}$ in fissure; $\mathrm{p}=0.04$ ). In the group with neoplasm, the values of P1NP decreased $6 \%$ after HBOT (T0: $49 \pm 31 \mathrm{ng} / \mathrm{mL}, \mathrm{T} 2: 46$ $\pm 12 \mathrm{ng} / \mathrm{mL} ; \mathrm{p}=0.03)$. Also, there were non-significant decreases in PTH $(-34 \%)$ and CTX (-30\%).

Conclusions: Patients with neoplasm and complications with radiotherapy have an increase in bone remodeling that may be diminished after HBOT.

Key words: hyperbaric oxygen therapy; neoplasm; radiotherapy; bone turnover markers Rep Pract Oncol Radiother 2021;26(2):163-169

\section{Introduction}

Oxygen is critical for maintaining bone cellular functions and changes in partial pressure of oxygen directly impact bone cell function [1]. Hypoxia is associated with excessive bone resorption, decreasing formation and mineralization $[2,3]$. However, hyperoxia could have opposite effects, regulating the expression of the hypoxia-inducible factor $1 \alpha$ (HIF-1 $\alpha$ ) [4], increasing formation and decreasing bone resorption [5-8]. The change of bone turnover rate could affect the bone quality. Hyperbaric oxygen therapy (HBOT) has shown to be useful for the treatment of patients with neoplasms and

Address for correspondence: Zaida Salmón González, Department of Internal Medicine, University Hospital Marqués de Valdecilla, Avenida de Valdecilla s/n, 39008 Santander, Spain; e-mail: mirvdc@humv.es, zaidasg@hotmail.com

This article is available in open access under Creative Common Attribution-Non-Commercial-No Derivatives 4.0 International (CC BY-NC-ND 4.0) license, allowing to download articles and share them with others as long as they credit the authors and the publisher, but without permission to change them in any way or use them commercially 
secondary complications from radiotherapy [9-11] due to its anti-inflammatory and antioxidant effects [12-16]. However, the actions of HBOT on bone metabolism in these patients are unknown.

In our study we aimed to analyze the effects of HBOT on bone remodeling in oncological patients that had been treated with radiotherapy.

\section{Materials and methods}

Prospective study (October 2018-October 2019) in 23 patients with neoplasms undergoing treatment with HBOT and 25 patients with chronic anal fissure (control group) who will also receive HBOT. The mean age of all patients was $60 \pm 14$ yrs. (range $30-87$ yrs.; $60 \%$ males). In all cases, the indication to receive treatment with HBOT was made by their specialist doctor (radiation oncologist, oncologist, general surgeon and gastroenterologist). 23 patients had neoplasm history but, without bone metastases ( 9 adenocarcinomas of the rectum or colon, 5 carcinomas of the head and neck, 3 carcinomas of the prostate, 3 gynecological adenocarcinomas, 2 cutaneous carcinomas and 1 ductal carcinoma of the breast), all with complications due to radiotherapy (cystitis $30 \%$, proctitis $30 \%$ and radionecrosis $40 \%$ ). The patients with chronic anal fissure received HBOT after not improving with conventional treatment.

The average total radiotherapy dose was $50.7 \mathrm{~Gy}$ in all patients with tumors. In pelvic tumors it was 44-50.4 Gy (1.8-2 Gy/fraction) to the pelvis (tu- mor/tumor bed and lymphatic areas), one patient received also $15 \mathrm{~Gy} /$ fraction with high dose rate brachytherapy as boost. In head and neck cancer it was $70 \mathrm{~Gy}(2 \mathrm{~Gy} /$ fraction) to the tumor and pathological nodes and 63-45 Gy (1.8-2 Gy/fraction) to the latero-cervical chains and supraclavicular fossa. In others tumors, the dose was $35 \mathrm{~Gy}$ (7 Gy/fraction).

We excluded pregnant women and patients with previous HBOT. The patients were exposed to HBOT inside a hyperbaric chamber (Galeazzi, Italy; $100 \%$ oxygen; 2.4 atmospheres absolute for 90 min. Fig. 1) while breathing through an oral-nasal mask 5 times a week. All subjects were evaluated prospectively. At baseline, clinical data were collected on standardized data forms. The determinations in both groups were obtained at three time points: T0 (before beginning HBOT), T1 (at the end of HBOT) and T2 (6 months after HBOT). The average number of HBOT sessions in all patients was $20 \pm 5$ (range 8-31), similar in both groups ( $21 \pm 4$ in neoplasm and $19 \pm 4$ in anal fissure).

The study protocol was approved by the Institutional Review Board and all patients gave their written informed consent.

Blood samples were obtained in a fasting state between 08:30 and 12:00 am. Routine chemistries were analyzed the same day. Other parameters were analyzed in serum aliquots stored at $-80^{\circ} \mathrm{C}$. Serum total calcium, creatinine, alkaline phosphatase (AP), phosphorus and albumin were determined by standard automated methods in an ADVIA 2400

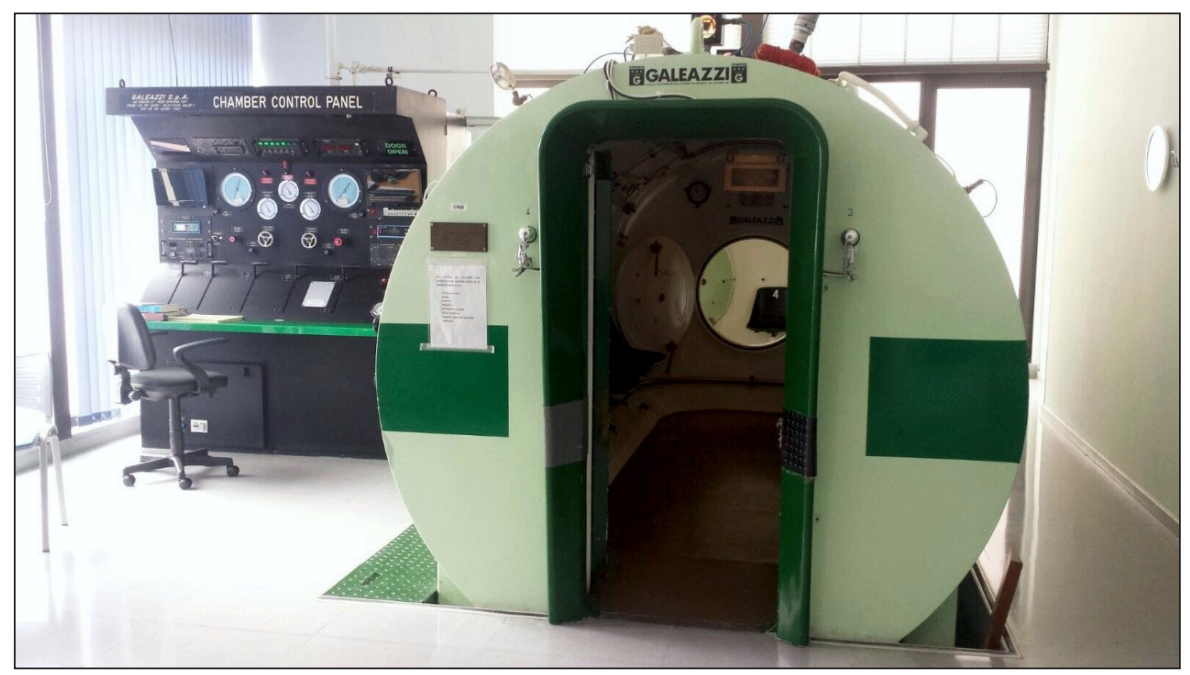

Figure 1. Hyperbaric oxygen therapy 
Chemistry System (Siemens Medical Solutions Diagnostics, Los Angeles, CA USA). Serum concentrations of 25hydroxyvitamin D (25-OHD), parathyroid hormone (PTH), aminoterminal propeptide of type I collagen (P1NP), and C terminal telopeptide of type I collagen (CTX) were determined by a chemiluminescent immunoassay in an iSYS (IDS-iSYS Multi-Discipline Automated Analyzer, Pouilly-en Auxois, France). The detection limit of serum $25 \mathrm{OHD}$ was $5 \mathrm{ng} / \mathrm{mL}$, its intra-assay coefficient of variation $(\mathrm{CV})$ was $<10$, and its inter-assay CV was $<15$. The detection limit of PTH was $6 \mathrm{pg} / \mathrm{mL}$, intra-assay and inter-assay CV were 2.6 and $5.8 \%$, respectively. The P1NP limit of detection was $0.14 \mathrm{ng} / \mathrm{mL}$ with an intra-assay and inter-assay CV of 2.9 and $4.7 \%$, respectively. The intra-assay and inter-assay CV of $\beta$-CTX were 3.2 and $6.2 \%$. The glomerular filtration rate was estimated using the new CKD-EPI equation from serum creatinine concentration.

\section{Statistical analysis}

The results were expressed as mean \pm SD for quantitative variables and percentage for qualitative variables. We used the Kolmogorov-Smirnov test to check for normal distribution. Quantitative variables were analyzed by Student $\mathrm{t}$ - test if the variables had a normal distribution, or the nonparametric Mann-Whitney U test were used to compare between-group differences. The Paired-Samples $\mathrm{T}$ Test or Wilcoxon tests were used to compare within-subject changes. The value of $p<0.05$ was considered statistically significant.

\section{Results}

Patients with neoplasm have at baseline (T0) higher bone turnover than those with anal fissure. These differences in T0 were $15 \%$ for alkaline phosphatase $(80 \pm 24 \mathrm{U} / \mathrm{L}$ in neoplasm and $68 \pm 16 \mathrm{U} / \mathrm{L}$ in fissure; $\mathrm{p}=0.04), 41 \%$ in CTX $(0.238 \pm 0.202$ $\mathrm{ng} / \mathrm{mL}$ in neoplasm and $0.141 \pm 0.116 \mathrm{ng} / \mathrm{mL}$ in fissure; $\mathrm{p}=0.04)$, and $30 \%$ for PTH $(46 \pm 36 \mathrm{pg} / \mathrm{mL}$ in neoplasm and $32 \pm 17 \mathrm{pg} / \mathrm{mL}$ in fissure; $\mathrm{p}=0.04$ ) (Fig. 2). The levels of P1NP (49 $\pm 31 \mathrm{ng} / \mathrm{mL}$ in neoplasm and $43 \pm 24 \mathrm{ng} / \mathrm{mL}$ in fissure; $\mathrm{p}=0.44$ ) and 25-OHD $(20 \pm 12 \mathrm{ng} / \mathrm{mL}$ in neoplasm and $19 \pm 11 \mathrm{ng} / \mathrm{mL}$ in fissure; $\mathrm{p}=0.72$ ) were similar. After HBOT (T1 and T2) the differences in CTX and PTH between both groups largely disappeared and were only maintained in alkaline phosphatase (Fig. 2).

In the neoplasm group there were no early changes (T1) after HBOT in values of bone turnover with respect to baseline, but there was a significant decrease in the bone formation marker (P1NP) after 6 months (T0:49 $\pm 31 \mathrm{ng} / \mathrm{mL}$ and T2:46 $\pm 12 \mathrm{ng} / \mathrm{mL}$; $\mathrm{p}=0.03)$. Also, we observed a non-significant decrease in PTH (34\%; T0: $46 \pm 36 \mathrm{pg} / \mathrm{mL}, \mathrm{T} 2: 30 \pm 14$ $\mathrm{pg} / \mathrm{mL} ; \mathrm{p}=0.62)$ and CTX (30\%; T0: $0.238 \pm 0.202$ $\mathrm{ng} / \mathrm{mL}, \mathrm{T} 2: 0.165 \pm 0.134 \mathrm{ng} / \mathrm{mL} ; \mathrm{p}=0.95)$ after 6 months of HBOT in these patients (Tab. 1).

In the group of chronic anal fissure, the values were similar through the whole study period and we saw no influence of HBOT (Tab. 2).

All patients included in the study presented a clinical improvement (85\% in cancer patients and $90 \%$ in patients with chronic anal fissures) with a decrease in pain and bleeding mainly.

\section{Discussion}

Bone turnover markers have an important role in bone metabolism. Measurement of P1NP appears to be a more sensitive marker of the bone formation rate and CTX of the bone resorption rate. The change of the bone turnover rate could affect the bone quality. Patients with neoplasms, with or without metastases, have an increase in bone remodeling; in bone resorption as well as in bone formation $[18,19]$. In our study baseline we found an increase in bone remodeling in patients with tumors who have not developed metastases. Radiotherapy may contribute to deregulating bone remodeling via different mechanisms $[20,21]$. Radiation-induced bone loss is a potential health concern for cancer patients undergoing radiotherapy [22]. In our study, the oncology patients are treated with radiotherapy despite the absence of metastases and all of them received treatment with HBOT due to complications of radiotherapy (cystitis, proctitis or radionecrosis).

On the other hand, HBOT has shown to be useful in the treatment of radiotherapy complications like hemorrhagic cystitis, secondary proctitis [9] or radiation-induced skin necrosis $[23,24]$ due to its anti-inflammatory, antioxidant and immunomodulatory effects [25]. In our study, we observed a significant decrease of P1NP, as a bone formation marker, as well as a tendency to decrease the bone 


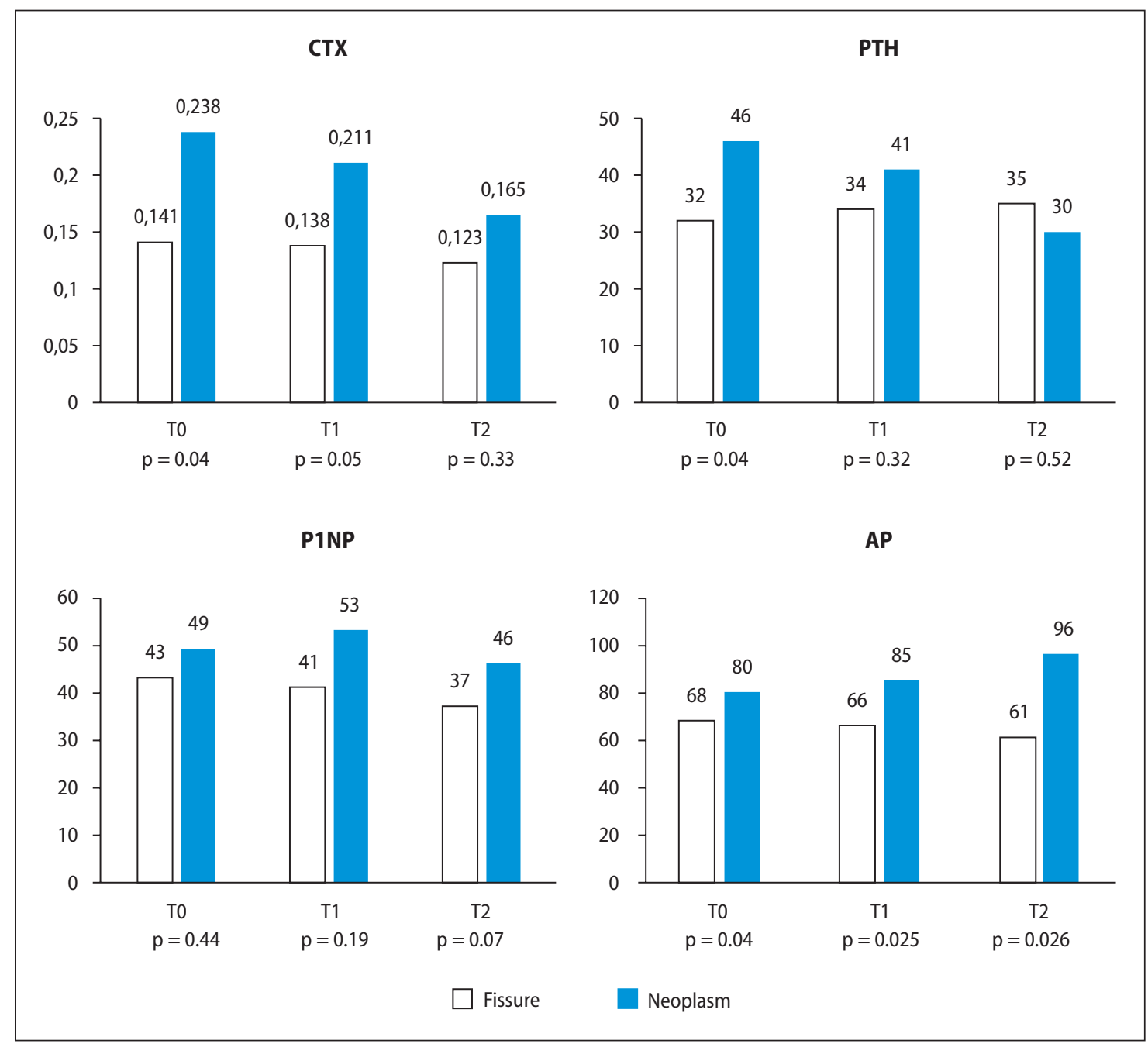

Figure 2. Bone metabolism in neoplasm and fissure; T0: before beginning HBOT, T1: at the end of HBOT, T2: 6 months after HBOT

Table 1. Bone metabolism in patients with neoplasm

\begin{tabular}{|c|c|c|c|}
\hline & TO & T1 & T2 \\
\hline Glomerular filtrate & $74(20)$ & $\begin{array}{c}77(19) \\
p=0.04\end{array}$ & $\begin{array}{l}81(14) \\
p=0.14\end{array}$ \\
\hline Albumin $[\mathrm{g} / \mathrm{dL}]$ & $4.2(0.3)$ & $\begin{array}{l}4.2(0.3) \\
p=0.90\end{array}$ & $\begin{array}{l}4.3(0.5) \\
p=0.55\end{array}$ \\
\hline Total calcium [mg/dL] & $9.1(0.4)$ & $\begin{array}{l}9.1(0.2) \\
p=0.38\end{array}$ & $\begin{array}{l}9.1(0.4) \\
p=0.90\end{array}$ \\
\hline Phosphorus [mg/dL] & $3.3(0.4)$ & $\begin{array}{l}3.2(0.4) \\
p=0.39\end{array}$ & $\begin{array}{l}3.0(0.3) \\
p=0.77\end{array}$ \\
\hline $25 \mathrm{OHD}[\mathrm{ng} / \mathrm{mL}]$ & $20(12)$ & $\begin{array}{c}20(12) \\
p=0.64\end{array}$ & $\begin{array}{c}18(9) \\
p=0.62\end{array}$ \\
\hline Alkaline phosphatase [U/L] & $80(24)$ & $\begin{array}{c}85(36) \\
p=0.58\end{array}$ & $\begin{array}{c}96(59) \\
p=0.08 \\
20 \%\end{array}$ \\
\hline
\end{tabular}


Table 1. Bone metabolism in patients with neoplasm

\begin{tabular}{|c|c|c|c|}
\hline & TO & $\mathrm{T1}$ & T2 \\
\hline P1NP [ng/mL] & $49(31)$ & $\begin{array}{c}53(34) \\
p=0.19\end{array}$ & $\begin{array}{c}46(12) \\
* p=0.03 \\
-6 \%\end{array}$ \\
\hline PTH $[p g / m L]$ & $46(36)$ & $\begin{array}{l}41(33) \\
p=0.06\end{array}$ & $\begin{array}{c}30(14) \\
p=0.62 \\
-34 \%\end{array}$ \\
\hline CTX [ng/mL] & $0.238(0.202)$ & $\begin{array}{c}0.211(0.144) \\
p=0.34\end{array}$ & $\begin{array}{c}0.165(0.134) \\
p=0.95 \\
-30 \%\end{array}$ \\
\hline
\end{tabular}

Mean (SD). T0: before beginning HBOT, T1: at the end of HBOT, T2: 6 months after HBOT; $\mathrm{p}$ value: corresponds to a statistically significant difference between TO and T1; * $p$ value: corresponds to a statistically significant difference between TO and T2; $\%$ - percentage of change

Table 2. Bone metabolism in patients with anal fissure

\begin{tabular}{|c|c|c|c|}
\hline & TO & T1 & T2 \\
\hline Glomerular filtrate & $87(7)$ & $\begin{array}{c}87(8) \\
p=0.37\end{array}$ & $\begin{array}{c}86(11) \\
p=0.11\end{array}$ \\
\hline Albumin $[\mathrm{g} / \mathrm{dL}]$ & $4.3(0.3)$ & $\begin{array}{l}4.3(0.3) \\
p=0.60\end{array}$ & $\begin{array}{l}4.3(0.2) \\
p=0.49\end{array}$ \\
\hline Total calcium [mg/dL] & $9.1(0.2)$ & $\begin{array}{l}9.0(0.2) \\
p=0.22\end{array}$ & $\begin{array}{l}9.0(0.2) \\
p=0.42\end{array}$ \\
\hline Phosphorus [mg/dL] & $3.3(0.5)$ & $\begin{array}{l}3.3(0.5) \\
p=0.85\end{array}$ & $\begin{array}{l}3.2(0.4) \\
p=0.73\end{array}$ \\
\hline $25 \mathrm{OHD}[\mathrm{ng} / \mathrm{mL}]$ & $19(11)$ & $\begin{array}{c}18(10) \\
p=0.33\end{array}$ & $\begin{array}{c}26(13) \\
p=0.13\end{array}$ \\
\hline Alkaline phosphatase [U/L] & $68(16)$ & $\begin{array}{c}66(16) \\
p=0.35\end{array}$ & $\begin{array}{c}61(17) \\
* p=0.06 \\
-10 \%\end{array}$ \\
\hline P1NP [ng/mL] & $43(24)$ & $\begin{array}{l}41(23) \\
p=0.41\end{array}$ & $\begin{array}{c}37(13) \\
p=0.19 \\
-14 \%\end{array}$ \\
\hline PTH $[\mathrm{pg} / \mathrm{mL}]$ & $32(17)$ & $\begin{array}{c}34(16) \\
p=0.75\end{array}$ & $\begin{array}{c}35(21) \\
p=0.85 \\
9 \%\end{array}$ \\
\hline CTX [ng/mL] & $0.141(0.116)$ & $\begin{array}{c}0.138(0.092) \\
p=0.64\end{array}$ & $\begin{array}{c}0.123(0.084) \\
p=0.46 \\
-12 \%\end{array}$ \\
\hline
\end{tabular}

Mean (SD). TO: before beginning HBOT, T1: at the end of HBOT, T2: 6 months after HBOT; $\mathrm{p}$ value: corresponds to a statistically significant difference between T0 and $\mathrm{T} 1 ; \mathrm{P}^{*}$ value: corresponds to a statistically significant difference between T0 and T2; $\%$ - percentage of change

resorption marker, in oncological patients after HBOT. The reduction of the inflammation in these complications (proctitis, cystitis and radionecrosis) after HBOT could be accompanied by a decrease in the remodeling in our patients, in this way establishing a relationship between inflammation and bone [26]. The fact that we found no changes in bone turnover after HBOT in patients with anal fissure, caused by internal anal sphincter hypertonia [27], may support this hypothesis.

Our study has several limitations because of the small sample size and we do not know if these results were generalized to other conditions and HBOT schedules. Nevertheless, to the best of our 
knowledge, this represents the first study that analyzes the effects of HBOT on bone turnover markers in patients.

In conclusion, patients with neoplasms and complications of RT have an increased bone remodeling. HBOT, in these patients, could have certain effects on bone homeostasis, but more studies are needed to elucidate the true effect of treatment with HBOT on bone metabolism and its long-term consequences.

\section{Conflict of interest}

Authors declare that they have no conflict of interest.

\section{Funding}

None declared.

\section{References}

1. Arnett TR. Acidosis, hypoxia and bone. Arch Biochem Biophys. 2010; 503(1): 103-109, doi: 10.1016/j. abb.2010.07.021, indexed in Pubmed: 20655868.

2. Utting JC, Flanagan AM, Brandao-Burch A, et al. Hypoxia stimulates osteoclast formation from human peripheral blood. Cell Biochem Funct. 2010; 28(5): 374-380, doi: 10.1002/cbf.1660, indexed in Pubmed: 20556743.

3. Al Hadi H, Smerdon GR, Fox SW. Hyperbaric oxygen therapy accelerates osteoblast differentiation and promotes bone formation. J Dent. 2015; 43(3): 382-388, doi: 10.1016/j. jdent.2014.10.006, indexed in Pubmed: 25456611.

4. Sunkari VG, Lind F, Botusan IR, et al. Hyperbaric oxygen therapy activates hypoxia-inducible factor 1 (HIF-1), which contributes to improved wound healing in diabetic mice. Wound Repair Regen. 2015; 23(1): 98-103, doi: 10.1111/ wrr.12253, indexed in Pubmed: 25532619.

5. Al Hadi H, Smerdon GR, Fox SW. Hyperbaric oxygen therapy suppresses osteoclast formation and bone resorption. J Orthop Res. 2013; 31(11): 1839-1844, doi: 10.1002/ jor.22443, indexed in Pubmed: 23878004.

6. Lin SS, Ueng SWn, Niu CC, et al. Effects of hyperbaric oxygen on the osteogenic differentiation of mesenchymal stem cells. BMC Musculoskelet Disord. 2014; 15: 56, doi: 10.1186/1471-2474-15-56, indexed in Pubmed: 24568330.

7. Lin SS, Ueng SWN, Niu CC, et al. Hyperbaric oxygen promotes osteogenic differentiation of bone marrow stromal cells by regulating $W n+3 a / \beta$-catenin signaling-an in vitro and in vivo study. Stem Cell Res. 2014; 12(1): 260-274, doi: 10.1016/j.scr.2013.10.007, indexed in Pubmed: 24291646.

8. Wu D, Malda J, Crawford R, et al. Effects of hyperbaric oxygen on proliferation and differentiation of osteoblasts from human alveolar bone. Connect Tissue Res. 2007; 48(4): 206-213, doi: 10.1080/03008200701458749, indexed in Pubmed: 17653977.
9. Hayne D, Smith AE. Hyperbaric oxygen treatment of chronic refractory radiation proctitis: a randomized and controlled double-blind crossover trial with long-term follow-up: in regard to Clarke et al. (Int J Radiat Oncol Biol Phys 2008 Mar 12). Int J Radiat Oncol Biol Phys. 2008; 72(5): 1621; author reply 1621, doi: 10.1016/j.ijrobp.2008.08.027, indexed in Pubmed: 19028292.

10. Oliai C, Fisher B, Jani A, et al. Hyperbaric oxygen therapy for radiation-induced cystitis and proctitis. Int J Radiat Oncol Biol Phys. 2012; 84(3): 733-740, doi: 10.1016/j. ijrobp.2011.12.056, indexed in Pubmed: 22440041.

11. Borab Z, Mirmanesh MD, Gantz M, et al. Systematic review of hyperbaric oxygen therapy for the treatment of radiation-induced skin necrosis. J Plast Reconstr Aesthet Surg. 2017; 70(4): 529-538, doi: 10.1016/j.bjps.2016.11.024, indexed in Pubmed: 28081957.

12. Atzeni F, Casale R, Alciati A, et al. Hyperbaric oxygen treatment of fibromyalgia: a prospective observational clinical study. Clin Exp Rheumatol. 2019; 37 Suppl 116(1): 63-69, indexed in Pubmed: 30747099.

13. Sultan A, Hanna GJ, Margalit DN, et al. The Use of Hyperbaric Oxygen for the Prevention and Management of Osteoradionecrosis of the Jaw: A Dana-Farber/Brigham and Women's Cancer Center Multidisciplinary Guideline. Oncologist. 2017; 22(3): 343-350, doi: 10.1634/theoncologist.2016-0298, indexed in Pubmed: 28209748.

14. Memar MY, Yekani M, Alizadeh N, et al. Hyperbaric oxygen therapy: Antimicrobial mechanisms and clinical application for infections. Biomed Pharmacother. 2019; 109: 440-447, doi: 10.1016/j.biopha.2018.10.142, indexed in Pubmed: 30399579.

15. Bennett MH, Feldmeier J, Hampson NB, et al. Hyperbaric oxygen therapy for late radiation tissue injury. Cochrane Database Syst Rev. 2005; 4(3): CD005005, doi: 10.1002/14651858.CD005005.pub2, indexed in Pubmed: 16034961.

16. Savvidou OD, Kaspiris A, Bolia IK, et al. Effectiveness of Hyperbaric Oxygen Therapy for the Management of Chronic Osteomyelitis: A Systematic Review of the Literature. Orthopedics. 2018; 41(4): 193-199, doi: 10.3928/0147744720180628-02, indexed in Pubmed: 30035798.

17. Levey AS, Stevens LA, Schmid CH, et al. CKD-EPI (Chronic Kidney Disease Epidemiology Collaboration). A new equation to estimate glomerular filtration rate. Ann Intern Med. 2009; 150(9): 604-612, doi: 10.7326/0003-4819150-9-200905050-00006, indexed in Pubmed: 19414839.

18. Fontana A, Delmas PD. Markers of bone turnover in bone metastases. Cancer. 2000; 88(12 Suppl): 2952-2960, doi: 10.1002/1097-0142(20000615)88:12+<2952::aidcncr11 > 3.0.co;2-m, indexed in Pubmed: 10898339.

19. Marin L, Koivula MK, Jukkola-Vuorinen A, et al. Comparison of total and intact aminoterminal propeptide of type I procollagen assays in patients with breast cancer with or without bone metastases. Ann Clin Biochem. 2011; 48(Pt 5): 447-451, doi: 10.1258/acb.2011.011040, indexed in Pubmed: 21733929.

20. Higham CE, Faithfull S. Bone Health and Pelvic Radiotherapy. Clin Oncol (R Coll Radiol). 2015; 27(11): 668-678, doi: 10.1016/j.clon.2015.07.006, indexed in Pubmed: 26276560.

21. Mavrogenis AF, Megaloikonomos PD, Panagopoulos $\mathrm{GN}$, et al. Side Effects of Radiation in Bone and Carti- 
lage: An FT-IR Analysis. J Long Term Eff Med Implants. 2015; 25(4): 289-295, doi: 10.1615/jlongtermeffmedimplants.2015011782, indexed in Pubmed: 26852637.

22. Zhang J, Wang Z, Wu A, et al. Differences in responses to $\mathrm{X}$-ray exposure between osteoclast and osteoblast cells. J Radiat Res. 2017; 58(6): 791-802, doi: 10.1093/jrr/rrx026, indexed in Pubmed: 28541506.

23. Oliai C, Fisher B, Jani A, et al. Hyperbaric oxygen therapy for radiation-induced cystitis and proctitis. Int $J$ Radiat Oncol Biol Phys. 2012; 84(3): 733-740, doi: 10.1016/j. ijrobp.2011.12.056, indexed in Pubmed: 22440041.

24. Borab Z, Mirmanesh MD, Gantz M, et al. Systematic review of hyperbaric oxygen therapy for the treatment of radiation-induced skin necrosis. J Plast Reconstr Aesthet Surg.
2017; 70(4): 529-538, doi: 10.1016/j.bjps.2016.11.024, indexed in Pubmed: 28081957.

25. Atzeni F, Casale R, Alciati A, et al. Hyperbaric oxygen treatment of fibromyalgia: a prospective observational clinical study. Clin Exp Rheumatol. 2019; 37 Suppl 116(1): 63-69, indexed in Pubmed: 30747099.

26. Adamopoulos IE. Inflammation in bone physiology and pathology. Curr Opin Rheumatol. 2018; 30(1): 59-64, doi: 10.1097/BOR.0000000000000449, indexed in Pubmed: 29016371.

27. Cundall JD, Gardiner A, Laden G, et al. Use of hyperbaric oxygen to treat chronic anal fissure. $\mathrm{Br} J$ Surg. 2003; 90(4): 452-453, doi: 10.1002/bjs.4054, indexed in Pubmed: 12673747. 